\title{
Impact of Cystic Fibrosis Transmembrane Regulator (CFTR) gene mutations on male infertility
}

\author{
Jlenia Elia ${ }^{1}$, Rossella Mazzilli ${ }^{1}$, Michele Delfino ${ }^{1}$, Maria Piane ${ }^{2}$, Cristina Bozzao ${ }^{2}$, Vincenzo Spinosa ${ }^{1}$, \\ Luciana Chessa $^{2}$, Fernando Mazzilli ${ }^{1}$ \\ ${ }^{1}$ Sant'Andrea Hospital, Unità di Andrologia, Department of Clinical and Molecular Medicine, University of Rome "Sapienza", \\ Rome, Italy; \\ 2 Sant'Andrea Hospital, Unità di Genetica Medica, University of Rome "Sapienza”, Rome, Italy.
}

\begin{abstract}
Summary Objective. The aim of this study was to evaluate the prevalence of most common mutations and intron 85 T (IVS8-5T) polymorphism of CFTR gene in Italian: a) azoospermic males; b) non azoospermic subjects, male partners of infertile couples enrolled in assisted reproductive technology (ART) programs.
\end{abstract}

Material and methods. We studied 242 subjects attending our Andrology Unit (44 azoospermic subjects and 198 non azoospermic subjects, male partners of infertile couples enrolled in ART programs). Semen analysis, molecular analysis for CFTR gene mutations and genomic variant of IVS8-5T polymorphic tract, karyotype and chromosome $Y$ microdeletions, hormonal profile (LH, FSH, Testosterone) and seminal biochemical markers (fructose, citric acid and L-carnitine) were carried out.

Results. The prevalence of the common CFTR mutations and/or the IVS8-5T polymorphism was $12.9 \%$ (4/31 cases) in secretory azoospermia, while in obstructive azoospermia was $84.6 \%$ (11/13 cases; in these, the most frequent mutations were the F508del, R117H and W1282X). Regarding the non azoospermic subjects, the prevalence of the CFTR and/or the IVS8-5T polymorphism was $11.1 \%$ (11/99 cases) in severe dyspermia, $8.1 \%$ (6/74 cases) in moderate dyspermia and finally $4.0 \%$ ( $1 / 25$ cases) in normospermic subjects.

Conclusions. This study confirms the highly significant prevalence of CFTR mutations in males with bilateral absence of the vas deferens or ejaculatory ducts obstruction compared with subjects with secretory azoospermia. Moreover, the significant prevalence of mutations in severely dyspermic subjects may suggest the possible involvement of CFTR even in the spermatogenic process. This could explain the unsatisfactory recovery of sperm from testicular fine needle aspiration in patients affected by genital tract blockage.

KEY WORDS: Semen analysis; Azoospermia; Male infertility; Molecular analysis; CFTR gene mutations; IVS8-5T polymorphic tract.

Submitted 27 December 2013; Accepted 15 May 2014

\begin{abstract}
INTRODUCTION
In recent years, increasing attention has been paid to the pathogenesis of dyspermia with a genetic basis $(1,2)$. In particular, after the development of Assisted Reproductive Techniques (ART), genetic screening has taken on an important role in the diagnostic approach to couple infertility. Regarding the male factor, in addition to the usual genetic investigations in clinical practice to identify factors, such as karyotype and chromosome Y microdeletions, the study of Cystic Fibrosis Transmembrane Regulator (CFTR) gene mutations, implicated in the genesis of Cystic Fibrosis (CF) (3), has acquired a great significance.

Beyond the classic aspects (pulmonary and pancreatic involvement) there are also atypical forms of $\mathrm{CF}$.

These atypical forms include male reproductive disorders. To date, a clear correlation with CFTR mutations has been demonstrated only in obstructive azoospermia due to Congenital Bilateral Absence of the Vas Deferens (CBAVD) (4-8). It has also been suggested that there is the direct involvement of the CFTR on spermatogenesis (9-15), and on pathogenesis of seminal hyperviscosity (17), as well as its having a potential action on the maturation of spermatozoa in vitro (16).

The aim of this study was to evaluate the prevalence of the common mutations and the IVS8-5T polymorphism of the CFTR gene in: a) azoospermic males and b) non azoospermic male partners of infertile couples enrolled in ART programs.
\end{abstract}

\section{Material AND MEtHodS}

\section{Subjects}

We studied 242 males attending our Andrology Unit from January 2005 to December 2012. Among these there were 44 azoospermic and 198 non azoospermic subjects, male partners of infertile couples taking part in ART programs.

Semen analysis

Semen analysis was performed in all the subjects at least twice at a distance of 30 days; the mean values were 
recorded and analyzed. The semen samples were collected by masturbation after 3-5 days of sexual abstinence. The samples were stored in a controlled incubator $\left(37^{\circ} \mathrm{C}\right)$. After liquefaction, semen samples were analyzed according to World Health Organization (WHO) guidelines (18). The Superimposed Image Analysis System (SIAS) was used to assess sperm motility parameters $(19,20)$. In azoospermic males three further tests, Fructose, L-Carnitine and Citric Acid were also carried out.

\section{Molecular analysis}

Written informed consent was obtained from each subject enrolled in this study. Genomic DNA was extracted from peripheral blood, according the standard procedure. Molecular analysis of the most frequent mutations of CFTR and the IVS8-5T polymorphic tract was performed by Inno-Lipa CFTR 19, CFTR 17+Tn Update and CFTR Italian Regional Kits (Innogenetics, Belgium), providing a screening for 57 CFTR gene mutations and following the manufactures instructions.

\section{Other analyses}

The hormonal profile was studied in all the subjects (LH, FSH, testosterone), as well as karyotype and chromosome Y microdeletions.

\section{Statistical analysis}

Statistical analysis was performed using the Chi-square test on frequency differences between two samples.

A $p$ value $<0.05$ was considered significant.

\section{Results}

Prevalence of mutations and polymorphism of CFTR gene in subjects with azoospermia.

Azoospermic males (n. 44) were divided into two groups: A) subjects with secretory azoospermia (n. 31); B) subjects with obstructive azoospermia (n. 13). The clinical examination, the hormonal profile, the biochemical study of seminal plasma (Fructose, L-Carnitine and Citric Acid as markers respectively of prostate, vesicles and epididymis), genetic screening, ultrasound examination and, when indicated, cytomorphological study by testicular needle aspiration permitted the differential diagnosis between secretory and obstructive azoospermia.

Secretive azoospermia (31 subjects) was due to: a) spermatogenic arrest (n.4); b) bilateral cryptorchidism, epididymo-orchitis and radio- or chemo-therapy (n.20); c) chromosomal anomalies (Klinefelter's and Robertsonian translocations) (5 cases); d) Y chromosome microdeletions (2 cases). Altogether in 4 of these 31 subjects (12.9\%) a classic mutation of CFTR and/or the IVS8-5T polymorphism were identified. In particular, one male (3.2\%) with previous cryptorchidism showed the most common mutation of the CFTR gene (F508 del), while in the other 3 subjects (9.7\%) was detected the IVS8-5T polymorphism.

Obstructive azoospermia (n. 13 subjects) was due to: a) obstruction of the vas deferens (n. 2); b) obstruction of the ejaculatory ducts (n. 10); epididymal obstruction, seen at surgery (n. 1). Altogether 11 of these 13 subjects (84.6\%) were affected by a classic mutation of the CFTR and/or the IVS8-5T polimorphysm. In particular, in 9 cases (69.2\%; $p<0.01$ vs secretory azoospermia) a classical mutation was found; in the remaining 2 cases (15.4\%) the IVS8-5T variant allele was found. The mutations found are listed in Table 1.

\section{Prevalence of mutations and 5T polymorphism of CFTR gene in non azoospermic males}

Genetic screening was carried out in 198 male partners of subfertile couples enrolled in programs of ART. According to the seminal profile, the subjects were subdivided into: a) severe dyspermia (n. 99) (seminal parameters: $\mathrm{N} / \mathrm{ml} \leq 5 \times 10^{6}, \leq 5$ progressive motility; atypical forms $\geq 85 \%$ ); b) moderate dyspermia (74); c) normospermia (n. 25) (WHO guidelines 1999) (18).

Table 1.

Genotype-phenotype correlation in males with obstructive azoospermia.

\begin{tabular}{|c|c|c|c|c|c|c|c|c|c|c|c|c|}
\hline \multirow[b]{2}{*}{ Subjects } & \multirow[b]{2}{*}{$\begin{array}{c}\text { CFTR } \\
\text { genotype }\end{array}$} & \multirow[b]{2}{*}{$\begin{array}{c}\text { Site } \\
\text { of obstruction }\end{array}$} & \multirow[b]{2}{*}{ Karyotype } & \multirow[b]{2}{*}{$\begin{array}{l}\text { Microdel } \\
\text { Crom Y }\end{array}$} & \multicolumn{3}{|c|}{ Hormonal profile } & \multirow[b]{2}{*}{$\mathrm{pH}$} & \multirow[b]{2}{*}{$\begin{array}{l}\text { Vol eiac. } \\
\text { (ml) }\end{array}$} & \multicolumn{2}{|c|}{ Biochemistry } & \multirow[b]{2}{*}{$\begin{array}{c}\text { Citric Acid } \\
\text { (mg/dl) }\end{array}$} \\
\hline & & & & & $\begin{array}{l}\text { FSH } \\
\mathrm{mU} / \mathrm{ml}\end{array}$ & $\begin{array}{c}\text { LH } \\
\mathrm{mU} / \mathrm{ml}\end{array}$ & $\begin{array}{l}\text { Test. } \\
\mathrm{ng} / \mathrm{ml}\end{array}$ & & & $\begin{array}{l}\text { Fructose } \\
(\mathrm{mg} / \mathrm{dl})\end{array}$ & $\begin{array}{l}\text { L-Carnitine } \\
\text { (mg/dl) }\end{array}$ & \\
\hline 1 & F508del/N & Ejaculatory duct & $46, X Y$ & Negative & 4.9 & 3.2 & 5.1 & 6.3 & 0.4 & 10 & 0.4 & 1100 \\
\hline 2 & F508del/N & Ejaculatory duct & $46, X Y$ & Negative & 4.8 & 5.4 & 5.6 & 6.7 & 0.5 & 20 & 0.2 & 1200 \\
\hline 3 & F508del/N & Ejaculatory duct & $46, X Y$ & Negative & 5.3 & 2.8 & 6.7 & 6.5 & 0.4 & 10 & 0.3 & 1100 \\
\hline 4 & F508del/5T & Ejaculatory duct & $46, X Y$ & Negative & 6.4 & 5.8 & 2.9 & 6.5 & 0.3 & 30 & 0.3 & $>1200$ \\
\hline 5 & F508del/5T & Vas deferens & $46, X Y$ & Negative & 5.6 & 4.9 & 3.9 & 6.5 & 0.4 & 20 & 0.4 & $>1200$ \\
\hline 6 & R117H/N & Vas deferens & $46, X Y$ & Negative & 6.5 & 4.7 & 4.9 & 6.5 & 0.5 & 210 & 0.1 & 1100 \\
\hline 7 & $\mathrm{D} 1152 \mathrm{H} / \mathrm{N}$ & Ejaculatory duct & $46, X Y$ & Negative & 5.2 & 3.9 & 3.8 & 6.5 & 0.4 & 10 & 0.1 & 1200 \\
\hline 8 & L1065P/N & Intra-epididymal & $46, X Y$ & Del AZF b & 11.3 & 9.8 & 3.4 & 6.7 & 0.3 & 10 & 0.4 & 1200 \\
\hline 9 & W1282X/N & Ejaculatory duct & $46, X Y$ & Negative & 4.7 & 5.1 & 5.8 & 7.4 & 2.1 & 180 & 0.1 & 450 \\
\hline 10 & $5 \mathrm{~T} / \mathrm{N}$ & Ejaculatory duct & $46, X Y$ & Negative & 3.9 & 2.8 & 6.5 & 6.0 & 0.2 & 20 & 0.3 & $>1200$ \\
\hline 11 & $5 \mathrm{~T} / \mathrm{N}$ & Ejaculatory duct & $46, X Y$ & Negative & 4.2 & 7.1 & 2.8 & 6.7 & 0.3 & 10 & 0.2 & $>1200$ \\
\hline
\end{tabular}


Table 2.

Genotype-phenotype correlation in males with severe dyspermia.

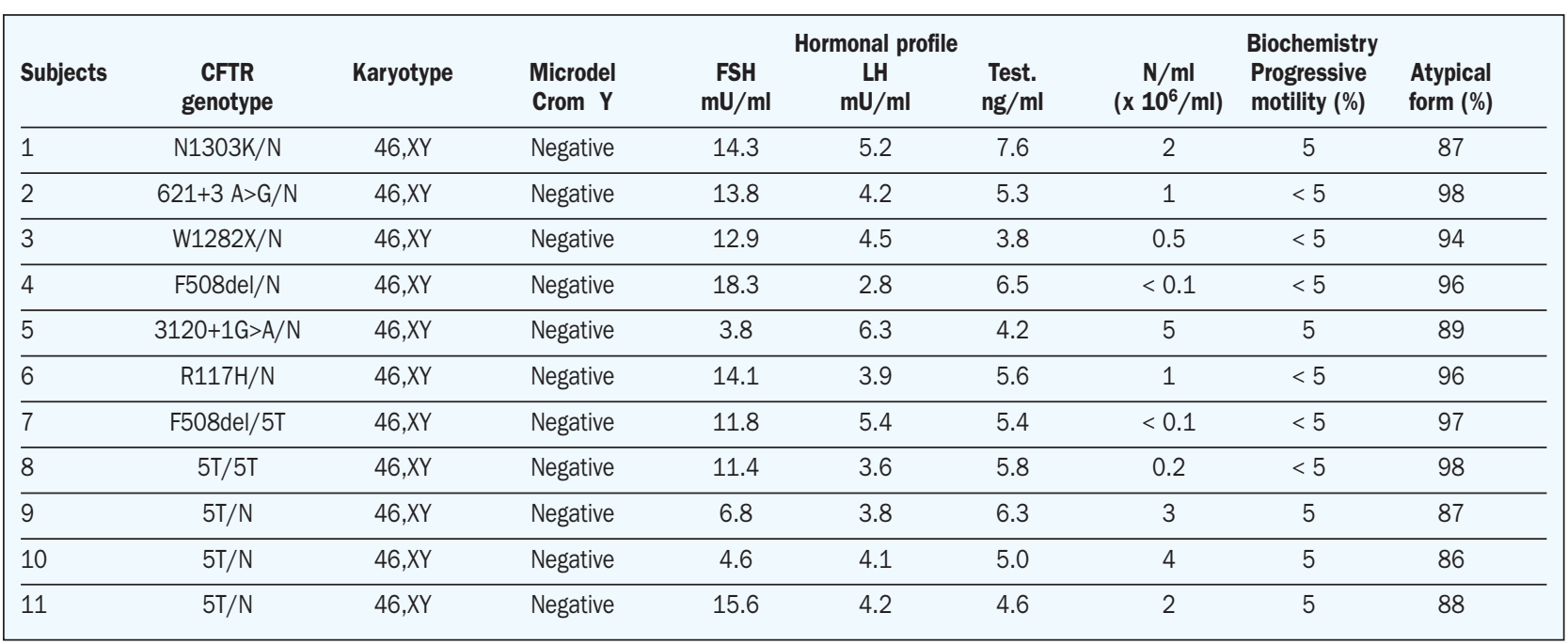

In subjects with severe dyspermia (n. 99), 11 cases (11.1\%) showed a classic mutation and/or the IVS8-5T polymorphism. In particular, 7 subjects ( $7.1 \%$; $p=0.465$ vs moderate dyspermia) had a classic mutation (one of them was compound heterozygous F508del/5T), 1 male was homozygote $5 \mathrm{~T} / 5 \mathrm{~T}(0.9 \%)$, and finally 3 subjects (2.7\%) were heterozygotes for the $5 \mathrm{~T}$ polymorphism (Table 2).

In subjects with moderate dyspermia (n. 74), 6 subjects (8.1\%) had a classic mutation of the CFTR gene and/or the IVS8-5T polymorphism; in particular, 2 subjects (2.7\%) were heterozygous W1282X/N and the R117H/N) and 4 subjects (5.4\%) had the 5T polymorphism.

In normospermic subjects (n. 25), only one moresubject (4.0\%) with 5T polymorphism was found.

\section{Discussion}

After the introduction of the ART programs, genetic screening gradually took on a leading role in the diagnostic process of infertility counselling. In fact, such techniques have "put in play" also couples with high genetic risk. Regarding genetic screening of the male partner, the search for mutations in the CFTR gene has become increasingly important.

In this study we evaluated the prevalence of mutations in the CFTR gene in subjects with seminal tract obstructions as well as in subjects with varying degrees of dyspermia.

Regarding the first group, our study confirmed the high prevalence of CFTR mutations in subjects with bilateral absence of the vas deferens or ejaculatory ducts obstruction. The most frequent mutations were, according to the literature, F508del, R117H and W1282X.

With regard to the male D1152H/N his partner carried the heterozygous genotype $621+3 \mathrm{~A}>\mathrm{G} / \mathrm{N}$. This opened a debate between operators on the opportunities and possibilities of using pre-implantation diagnosis as part of a program of assisted reproduction.

In disagreement with Karpman et al. (21), who reported significant association of CFTR mutations with Y chromosome microdeletion, in our study we found such association only in one case.

On the other hand, the prevalence of mutations in subjects with classical secretory azoospermia was significantly lower compared with obstructive azoospermia. The second part of the study was conducted on the prevalence of mutations and/or genomic variants in a population of male partners (dyspermic and normospermic) of subfertile couples enrolled in ART programs. There are sharply conflicting reports in the literature. According to some Authors (9-11) there are no significant changes in the prevalence of mutations or genomic variants of CFTR in subjects affected by moderate dyspermia and population controls. In partial agreement with other Authors (12-15) this study highlights a significant prevalence of mutations in the CFTR gene in males with severe dyspermia compared to normospermic ones.

\section{Conclusions}

In conclusion, this study confirms the direct involvement of the CFTR gene in the pathogenesis of seminal tract obstructions. The significant prevalence of mutations in severely dyspermic subjects may suggest the possible involvement of CFTR even in the spermatogenic process. This could explain the unsatisfactory recovery of sperm from testicular fine needle aspiration in patients affected by genital tract blockage.

\section{REFERENCES}

1. Mak V, Jarvi KA. The genetics of male infertility. J Urol. 1996; 156:1245-56.

2. Lee JY, Dada R, Carpi A, et al. Role of genetics in azoospermia. Urology, 2011; 77:598-601.

3. Knowles MR, Durie PR. What is cystic fibrosis? N Engl J Med, 2002; 347:439-42. 
4. Dohle GR, Veeze HJ, Overbeek SE, et al. The complex relationships between cystic fibrosis and congenital bilateral absence of the vas deferens: clinical, electrophysiological and genetic data. Hum Reprod. 1999; 14:371-4.

5. Chillon M, Casals T, Mercier B, et al. Mutations in the cystic fibrosis gene in patients with congenital absence of the vas deferent. N Eng J Med. 1995; 332:1475-80.

6. Jarzabek K, Zbucka M, Pepinski W, et al. Cystic fibrosis as a cause of infertility. Reprod Biol. 2004; 4:119-29.

7. Chen H, Ruan YC, Xu WM, et al. Regulation of male fertility by CFTR and implications in male infertility. Hum Reprod Update. 2012; 18:703-13

8. Mocanu E, Shattock R, Barton D, et al. All azoospermic males should be screened for cystic fibrosis mutations before intracytoplasmic sperm injection. Fertil Steril. 2010; 94:2448-50.

9. Riccaboni A, Lalatta F, Caliari I, et al. Genetic screening in 2,710 infertile candidate couples for assisted reproductive techniques: results of application of Italian guidelines for the appropriate use of genetic tests. Fertil Steril. 2008; 89:800-8.

10. Larriba S, Bonache S, Sarquella J, et al. Molecular evaluation of CFTR sequence variants in male infertility of testicular origin. Int $J$ Androl. 2005; 28:284-90.

11. Foresta C, Garolla A, Bartoloni L, et al. Genetic abnormalities among severely oligospermic men who are candidates for intracytoplasmic sperm injection. J Clin Endocrinol Metab. 2005; 90:152-6.

12. Mennicke K, Klingenberg RD, Bals-Pratsch, et al. Rational approach to genetic testing of cystic fibrosis (CF) in infertile men. Andrologia. 2005; 37:1-9.
13. Schulz S, Jakubicza S, Kropf S, et al. Increased frequency of cystic fibrosis transmembrane conductance regulator gene mutations in infertile males. Fertil Steril. 2006; 85:135-8.

14. Tamburino L, Guglielmino A, Venti E, et al. Molecular analysis of mutations and polymorphisms in the CFTR gene in male infertility. Reprod Biomed Online. 2008; 17:27-35.

15. Chan HC, Ruan YC, He Q, et al. The cystic fibrosis transmembrane conductance regulator in reproductive health and disease. $J$ Physiol. 2009; 587:2187-95.

16. Li CY, Jiang LY, Chen WY, et al. CFTR is essential for sperm fertilizing capacity and is correlated with sperm quality in human. Hum Reprod. 2010; 25:317-27.

17. Rossi T, Grandoni F, Mazzilli F, et al. High frequency of (TG)m Tn variant tracts in the cystic fibrosis transmenbrane conductance regulator gene in men with high semen viscosity. Fertil Steril. 2004; $82: 1316-22$

18. World Health Organization. WHO laboratory manual for the examination of human semen and sperm-cervical mucus interaction. 4th ed. Cambridge UK; New York NY; 1999.

19. Mazzilli F, Rossi T, Sabatini L, et al. Superimposed Image Analysis System (SIAS) software: a new approach to sperm motility assessment. Fertil Steril. 1995; 64:653-6.

20. Mazzilli F, Rossi T, Delfino M, et al. Application of the upgraded image superimposition system (SIAS) to the assessment of sperm kinematics. Andrologia. 1999; 31:187-94.

21. Karpman E, Williams DH, Wilberforce S, et al. Compound genetic abnormalities in patients with cystic fibrosis transmembrane regulator gene mutation. Fertil Steril. 2007; 87:1468.e5-8.

\section{Correspondence}

Jlenia Elia, MD

Rossella Mazzilli, MD

Michele Delfino, MD

Vincenzo Spinosa, MD

Fernando Mazzilli, MD (Corresponding Author)

fernando.mazzilli@uniromal.it

Sant'Andrea Hospital, Unit of Andrology, University of Rome, "Sapienza"

Via di Grottarossa 1035 - 00189 Roma, Italy

Maria Piane, MD

Cristina Bozzao, MD

Luciana Chessa, MD

Sant'Andrea Hospital, Unità Genetica Medica, University of Rome, "Sapienza"

Via di Grottarossa 1035 - 00189 Roma, Italy 